\title{
Carbon monoxide poisoning: easy to treat but difficult to recognise
}

\author{
Martin V Balzan, Gabriella Agius, Anthony Galea Debono
}

\begin{abstract}
Summary
Carbon monoxide (CO) poisoning is a common medical emergency and a frequent cause of deliberate or accidental death. It can cause acute and chronic central nervous system damage which may be minimised by prompt treatment with $100 \%$ oxygen or hyperbaric oxygen therapy. However, recognition of this intoxication can be difficult. Failure to diagnose it may have disastrous effects on the patient, and other members of the household who could subsequently become intoxicated. Guidance on the correct diagnosis of this condition is provided in the light of a number of studies screening emergency room populations. Guidelines for treatment with hyperbaric oxygen therapy are also reviewed.
\end{abstract}

Keywords: carbon monoxide poisoning

\begin{tabular}{|c|c|}
\hline \multicolumn{2}{|c|}{$\begin{array}{l}\text { Clinical features of } \mathrm{CO} \\
\text { poisoning and } \mathrm{CO}-\mathrm{Hb} \text { levels }\end{array}$} \\
\hline $\begin{array}{l}<10 \% \\
10-20 \%\end{array}$ & $\begin{array}{l}\text { asymptomatic } \\
\text { unstable angina in coronary } \\
\text { artery disease }\end{array}$ \\
\hline $20-30 \%$ & headache, vertigo \\
\hline $30-50 \%$ & $\begin{array}{l}\text { severe headache, vomiting, } \\
\text { disturbance of consciousness }\end{array}$ \\
\hline$>50 \%$ & $\begin{array}{l}\text { coma, convulsions, } \\
\text { respiratory depression, death }\end{array}$ \\
\hline
\end{tabular}

Department of Medicine, St Luke's Hospital, Guardamangia, Malta MV Balzan

G Agius

A Galea Debono
Carbon monoxide (CO) is produced from incomplete combustion of fossil fuel, cars being the most important environmental source. ${ }^{1,2}$ Indoor air pollution with CO may result from faulty kerosene or gas heaters used in unventilated areas, ${ }^{3}$ gas water heaters, or fireplaces with blocked flues. ${ }^{4}$ More unusual causes include barbecue cubes burnt indoors, ${ }^{5}$ small petrol electricity generators without proper emission disposal, or the use of forklift trucks in warehouses. ${ }^{6,7}$

Cigarette smoke contains small amounts of $\mathrm{CO}$, and it has been shown that smokers have higher baseline carboxyhaemoglobin (CO-Hb) levels than nonsmokers. 8,9

CO has a much higher affinity for the haemoglobin molecule than oxygen, thus replacing it and making it unavailable for oxygen transport. ${ }^{10}$ The oxygen dissociation curve is shifted to the left, making unloading of oxygen at the tissue level problematic. Furthermore, myoglobin in muscle and cytochromes in cells are partially inactivated. ${ }^{11,12}$ These effects result in generalised tissue hypoxia, the more susceptible tissues of the brain ${ }^{13}$ and myocardium ${ }^{14,15}$ being most commonly affected. $\mathrm{CO}$ also appears to cause brain lipid peroxidation. ${ }^{13}$

\section{Clinical presentation}

The clinical features of $\mathrm{CO}$ intoxication are very nonspecific and mimic common conditions causing, unconsciousness, epileptic fits, ${ }^{16,17}$ headache, ${ }^{18,19}$ flu-like illness, ${ }^{20}$ and unstable angina. ${ }^{21}$ It is important to recognise $\mathrm{CO}$ poisoning for two reasons. Firstly, patients presenting with coma or fits, or impairment of consciousness due to serious intoxication, if not treated promptly with hyperbaric oxygen or $100 \%$ oxygen therapy, may either not survive, or else survive to develop long-term neurologic and psychiatric problems. ${ }^{22}$ Secondly, recognition of the patient with less serious intoxication, presenting with minor complaints such as headache or flu-like illness, is important mainly to identify the source of the $\mathrm{CO}$ and thus prevent subsequent potentially catastrophic, exposures in the household. ${ }^{4,7,16,23,24}$

A number of studies screening emergency room populations have been published, suggesting a rational approach to the recognition of intoxication. Serious intoxication, on which hyperbaric oxygen is likely to have a clear therapeutic impact, presents with acute neurological features. ${ }^{25}$ Heckerling et al screened 168 consecutive acute neurological admissions and found one serious intoxication which possibly needed hyperbaric oxygen, and four minor intoxications, two of which were identified out of 43 admissions for epileptic fits. ${ }^{26}$

At our hospital (St Luke's, Malta) we screened 307 acute neurological admissions from December 1994 to April 1995. Out of 29 patients admitted with impaired consciousness and no lateralising neurological signs, three had serious intoxication, all of whom had bilateral upgoing plantars. (Heckerling ${ }^{26}$ had observed two cases of intoxication out of 81 patients screened in this diagnostic category.) However, out of 141 patients with presumed stroke or transient ischaemic attack, none had evidence of intoxication. Furthermore, out of 87 patients admitted with episodes of loss of consciousness who had recovered completely in the emergency room, none had evidence of intoxication.

In another study, Heckerling et al ${ }^{27}$ screened 753 acute surgical, medical, neurological, and psychiatric admissions. Only two minor cases of intoxication were identified. None of the patients with stroke had CO intoxication. However, out of 20 patients admitted with epileptic fits, one had evidence of acute exposure, a similar proportion to that found in the study mentioned above. ${ }^{26}$ In our study, none of the 39 patients with epileptic fits had evidence of CO exposure.

In a third study, Heckerling showed that $3-5 \%$ of patients presenting to an emergency department with headache, ${ }^{18}$ had occult CO exposure. The author 
Difficulties in the diagnosis of CO poisoning

- gas is colourless, odourless and non-irritant

- patient may be unaware of the exposure

- ambulance staff, co-habitants unaware of exposure

- patient with impaired consciousness unable to give history

- no pathopneumonic feature of the intoxication (textbook cherry red colour, a rare finding)

- mimics common conditions such as unstable angina, drug overdosage, status epilepticus

- patients with underlying cardiovascular and cerebrovascular disease can have an atypical presentation also validated a prediction model showing that a good history on indoor heating and the presence of symptomatic co-habitants correctly identified affected individuals. ${ }^{28}$ During the winter months, Dolan et $a l^{20}$ screened 55 inner-city inhabitants who presented with flu-like symptoms, ie, headache, nausea, and malaise. Thirteen had evidence of exposure to $\mathrm{CO}$, although none needed hyperbaric oxygen. In our opinion, Heckerling's suggestion to screen by history is preferable to routine assessment of $\mathrm{CO}-\mathrm{Hb}$ levels, as the expense of screening every individual with a common cold would be prohibitive. However, Dolan's data suggest that it is more likely that exposed patients who present to the emergency department will be discharged than admitted, so that a high index of suspicion must not be restricted to patients being admitted to hospital.

In a study screening 103 patients routinely admitted for coronary care with unstable angina, ${ }^{21}$ we found three cases of serious intoxication, and five of minor exposure. Although most emergency room physicians aim for quick, efficient, admissions, we suggest that information on the type of indoor heating used should be obtained in all cases so that treatment with $100 \%$ oxygen can be implemented when necessary.

When assessing patients presenting with impairment of consciousness, a common pitfall leading to a missed diagnosis of $\mathrm{CO}$ poisoning is the presence of underlying chronic cerebrovascular or metabolic problems. Not only may the clinical picture be atypical and occur at $\mathrm{CO}-\mathrm{Hb}$ levels of $10-20 \%$, but a readily available alternative explanation stops one from considering $\mathrm{CO}$ intoxication. For example, among our acute neurological emergencies, was a frail 75-yearold woman with diabetic neuropathy and nephropathy who presented with unconsciousness. The preliminary diagnosis was hypo-, or hyperglycaemia and uraemia. However, screening showed she had CO intoxication which was later shown to be due to a faulty kerosene heater. In our opinion, information on indoor heating must be obtained from members of the household in all patients admitted to hospital with impaired consciousness and no focal neurological signs. If no information is available, $\mathrm{CO}-\mathrm{Hb}$ levels should be obtained.

\section{Diagnosis and treatment}

Whenever $\mathrm{CO}$ intoxication is suspected $\mathrm{CO}-\mathrm{Hb}$ levels should be determined using spectrophotometric analysis in a $\mathrm{CO}$ oximeter. This test is easy to perform and should be available to all emergency room physicians. The result must be delivered as soon as possible to allow rational planning of therapy. When a $\mathrm{CO}$ oximeter is not available a hand-held $\mathrm{CO}$ expired air detector can be used to confirm the diagnosis. ${ }^{29,30}$ Two important pitfalls must be kept in mind. Firstly, arterial pO2, which reflects oxygen physically dissolved in plasma, is normal unless lung complications arise. Secondly, pulse oximetry is unreliable because of falsely high readings due to the erroneous detection of $\mathrm{CO}-\mathrm{Hb}$ as oxyhaemoglobin. ${ }^{31}$

The two main treatment modalities are $100 \%$ oxygen at atmospheric or at hyperbaric pressure. The rationale of this therapy is that the hypoxic insult to the tissues is greatly diminished by increasing the amount of oxygen dissolved in the blood and by markedly shortening the half-life of $\mathrm{CO}-\mathrm{Hb}$. $^{2,32,33}$

Although hyperbaric oxygen offers theoretical advantages over $100 \%$ oxygen therapy, it is not so widely available, takes a considerable time to organise, and can have a number of adverse effects. ${ }^{32}$ Furthermore, a Japanese study in $1977^{34}$ found that half of the patients treated for intoxication and coma with hyperbaric oxygen still had neurological sequellae. However, it is possible that by reducing mortality, hyperbaric oxygen actually increased overall morbidity. Clinical experience and a number of reported series have all documented a visible clear-cut improvement with hyperbaric oxygen in seriously intoxicated patients. ${ }^{35,36}$ Furthermore, the threat of litigation exists if hyperbaric oxygen is not delivered. ${ }^{35,37}$ A recent prospective randomised study comparing the outcome of patients treated at atmospheric pressure with those treated with hyperbaric oxygen has now provided convincing evidence for the utility of the latter in preventing neurological sequellae, even in moderate poisoning. ${ }^{38}$

A number of guidelines have been developed for the use of hyperbaric oxygen. ${ }^{25,33,36,39}$ When the diagnosis of CO poisoning is suspected, $100 \%$ oxygen treatment should be started immediately, without waiting for the CO$\mathrm{Hb}$ results. Patients with coma, fits, prolonged loss of consciousness or myocardial instability should receive hyperbaric oxygen. If the peak levels of $\mathrm{CO}-\mathrm{Hb}$ are more than $25 \%$ hyperbaric oxygen is recommended, even for minor symptoms. In children and pregnant women, more liberal use of hyperbaric oxygen is recommended; a lower cut-off point of $20 \%$ and possibly less is suggested, as both children and the fetus have a greater susceptibility to hypoxia. $^{40-42}$ 


\section{Treatment of $\mathrm{CO}$ poisoning}

Objective

- to reduce mortality rate, and reduce the frequency of long-term neuropsychiatric sequellae in survivors

Rationale of hyperbaric oxygen therapy

- greatly increases the amount of oxygen physically dissolved in the plasma

- shortens the half-life of $\mathrm{CO}-\mathrm{Hb}$ from 4-5 $\mathrm{h}$ in room air to $20-25 \mathrm{~min}$ for $100 \%$ oxygen at $2-3 \mathrm{~atm}$

Indications for hyperbaric oxygen therapy

- impaired consciousness (even if transitory) or fits

- cardiovascular instability. ECG evidence of ischaemia or arrhythmias

- peak CO-Hb above $25 \%$ even with minor symptoms

- children or pregnant women, $\mathrm{CO}$ $\mathrm{Hb}$ above $20 \%$ or if persistently symptomatic

Contraindications for hyperbaric therapy

- prolonged resuscitation with external cardiac compressions

- pulmonary disorders, ie, emphysema and chronic bronchitis

Complications of hyperbaric therapy

- barotrauma to tympanic membrane

- decompression sickness

- tension pneumothorax

Complications of $\mathrm{CO}$ poisoning

- cerebral oedema

- cardiac instability with or without heart failure

- visceral ischaemia

- rhabdomyolysis with renal failure
The recommended regime is $100 \%$ oxgyen administered at $2-3$ atmospheres for about $90-120$ minutes, ${ }^{25}$ followed by four hours of $100 \%$ oxygen therapy. Further hyperbaric oxygen treatments at eight-hourly intervals are recommended if neurological symptoms persist. Indeed one study has shown that multiple sessions are superior to single sessions. ${ }^{43} \mathrm{~A}$ recent study using a two-hour hyperbaric regime used once showed a much lower frequency of residual neurological problems than after normobaric therapy. ${ }^{38}$

Levels of $10-20 \% \mathrm{CO}-\mathrm{Hb}$ rarely cause serious illness, so it is preferable to treat with $100 \%$ oxygen for two to four hours, as hyperbaric oxygen usually takes about an hour to organise by which time treatment with $100 \%$ oxygen would have rendered it unnecessary. When unstable angina is the result of low grade intoxication superimposed on coronary artery disease, we feel that $100 \%$ oxygen at atmospheric pressure is sufficient. ${ }^{21}$ However, myocardial toxicity in young healthy patients indicates severe intoxication in which case hyperbaric oxygen is necessary. ${ }^{25}$

Hyperbaric therapy has occasionally been shown to cause baro trauma to the tympanic membrane. ${ }^{39,44}$ It should be avoided after cardiopulmonary resuscitation with external chest compression, ${ }^{45}$ pulmonary emphysema, and asthma, as a life-threatening pneumothorax may develop. ${ }^{39}$ Probably, frail elderly patients are more safely treated at atmospheric pressure.

Supportive therapy is very important in acute intoxication. Severely intoxicated patients may need intubation, mechanical ventilation, and intensive care. However the majority of patients do well with hyperbaric oxygen. We monitor patients who do not need intubation in a coronary care unit. The hypoxic injury to the brain commonly results in an anoxic encephalopathy with cerebral oedema. For this reason, intravenous dexamethasone with an $\mathrm{H} 2$ antagonist such as cimetidine is usually given soon after admission. ${ }^{46}$

A number of patients with intoxication are found by a passer-by after a period of time. In a warm environment rapid dehydration can ensue, resulting in hypotension and peripheral vasoconstriction. In such circumstances it is possible that the resultant ischaemia and hypoxia in the skin, ${ }^{47}$ viscera, ${ }^{48}$ and muscles $^{49}$ may actually be more severe and prolonged than in the brain and heart. For this reason a balance must be struck between rapid rehydration and the minimisation of cerebral oedema. A number of cases of abdominal visceral infarction have been documented. ${ }^{48}$ Skin lesions have also been reported, ${ }^{47}$ but the most commonly reported complication is muscle rhabdomyolysis due to skeletal muscle hypoxia. This can result in serious renal impairment. ${ }^{49}$

\section{Neurological sequellae: prognostic factors}

Neurological deficits can be of two types, immediate, due to the acute anoxic encephalopathy, or delayed, caused by late demyelination ${ }^{50}$ secondary to the primary hypoxic neuronal injury. Min $^{51}$ reviewed 2967 patients admitted to hospital with CO poisoning, $86(2.7 \%)$ of whom had long-term neuropsychiatric symptoms. However, $\mathrm{Choi}^{52}$ reports a frequency of $11.8 \%$, with a mean onset of symptoms 22 days post-exposure. A longitudinal study on 100 patients using extensive neuropsychiatric testing showed a frequency of $63 \%$ in those treated with $100 \%$ oxygen and $13 \%$ in those treated with multiple sessions of hyperbaric oxygen. ${ }^{43}$

Clinically, a broad range of neuropsychiatric abnormalities have been observed, such as dementia, psychosis, personality change and concentration deficit. Gait disturbance, faecal or urinary incontinence, mutism, memory loss, and visual disturbance appear to be the commonest neurological problems. Parkinsonism appears to be one of the rare sequellae. ${ }^{51}$

Autopsy studies have shown that the classical lesion of acute $\mathrm{CO}$ intoxication is symmetrical necrosis of the globus pallidum. ${ }^{53} \mathrm{~A}$ magnetic resonance imaging (MRI) study of 15 patients with delayed encephalopathy ${ }^{50}$ suggests that it is probably due to a diffuse reversible demyelinating process of white matter. A significant correlation between cerebral white matter changes on computed tomography scan and the development of delayed neurological sequellae has been documented. ${ }^{54}$

There are a number of clinical risk factors for delayed encephalopathy. The $\mathrm{CO}-\mathrm{Hb}$ level does not seem to be related. However, old age, coma lasting two or three days, and persistent dizziness and fatigue after regaining consciousness are thought to predict problems. ${ }^{55}$ It is advisable to give multiple cycles of hyperbaric oxygen in these cases unless contraindicated. It appears that proton magnetic resonance spectroscopy can determine neurological viability before actual demyelination is observed on MRI. ${ }^{56}$ However, the role of this technique and the value of hyperbaric oxygen at that stage still has to be determined in prospective studies. 
1 Ayres SM, Evans R, Licht D, et al. Health effects of exposure to high concentrations of automotive emissions. Arch Environ Health 1973; 27: 16877.

2 Hampson NB, Norkool DM. Carbon monoxide poisoning in children riding in the back of poisoning in children riding in the back

3 pickup trucks. FAMA. 1992; 267: 538-40. an infant exposed to kerosene heater. $\mathcal{F}$ Paediatrics 1983; 103: 249-51.

4 Kelley JS, Sophocleus GJ. Retinal hemorrhages in sub-acute carbon monoxide poisoning: Exposures in homes with blocked furnace flues. fAMA 1978; 239: 1515-7.

5 Hampson NB, Kramer CC, Dunford RG, Norkdool DM. Carbon monoxide poisoning
from indoor burning of charcoal briquets. $\mathcal{F A M} A$ 1994; 271: 52-3.

6 Baron RC, BackerRC, Sophers IM. Fatal unintended carbon monoxide poisoning in west Virginia from non-vehicular sources. $A m \mathcal{F} \mathrm{Pub}$ Health 1989; 1656.

7 Wesley Ely E, Moorhead B, Haponik EF. Warehouse workers headache: emergency evaWarehouse workers headache: emergency eva-
luation and management of 30 patients with carbon monoxide poisoning. Am $7 \mathrm{Med} 1995$; carbon mon $145-55$.

8 Stewart RD, Baretta ED, Platte LR, et al. Carboxy-haemoglobin levels in American blood donors. FAMA 1974: 229; 1187-95.

9 Wald N, Idle M, Smith PG, Bailey A. Carboxyhaemoglobin levels in smokers of filter and plain cigarettes. Lancet 1977: I; 110-1.

10 Haldane JS. The causes of anoxaemia. In: Respiration. New Haven: Yale University Press, 1922; pp 158-70.

11 Coburn RF. Mechanisms of carbon monoxide toxicity. Prev Med 1979; 8: 310-22

12 Meyers RAM, Lindberg SE, Crowley RA, et al. Carbon monoxide poisoning. The injury and its treatment. $\mathcal{f} \mathrm{Am}$ Coll Emerg Physicians 1979; 8: 479-84.

13 Ginsberg MD. Carbon monoxide intoxication. Clinical features, neuropathology and mechanisms of injury. Clin Toxicol 1985; 23: 281-8.

14 Ayers SM, Giannelli S, Muller H. Myocardial and sytemic response to carboxy-haemoglobin. Ann NY Acad Sci 1970; 174: 268-293.

15 Schafer N, Smilay MG, Mcmillan FP. Primary myocardial disease in man resulting from acute carbon monoxide poisoning. Am $\mathcal{F} \mathrm{Med} 1965$; 38: 316-20.

16 Burney RE, Wu SC, Nemiroff MJ.Carbon monoxide poisoning: clinical effects and results of treatment in 184 victims. Ann Emerg Med 1982; 11: 394-9.

17 Durnin C. Carbon monoxide poisoning presenting with focal epileptiform seizures. Lancet 1987; 1: 1319 .

18 Heckerling PS. Occult carbon monoxide poisoning: a cause of winter headache. $A m \mathcal{F}$ Emerg Med 1987; 5: 201-4.

19 Heckerling PS, Leikin JB, Maturen A, et al. Predictors of occult carbon monoxide poisoning in patients with headache and dizziness. Ann Intern Med 1987; 107: 174-6.

20 Dolan MC, Haltom TL, Barrows GH, et al. Carboxy-haemoglobin levels in patients with flulike symptoms. Ann Emerg Med 1987; 16: 782-6.

21 Balzan MV, Cacciottolo JM, Mifsud S. Unstable angina and exposure to carbon monoxide. Postgrad Med f 1994; 70: 699-702.
The prognosis of encephalopathy due to $\mathrm{CO}$ poisoning appears to be unfavourable. In one study, ${ }^{57}$ eight patients had a progressive deteriorating course after poisoning with a persistent akinetic mute state. Four died after one year. Out of 23 patients with delayed encephalopathy after initial improvement, 14 were bed-bound and with akinetic mutism and nine could walk but had severe cognitive impairment. After one year three had died but 14 patients had improved. Anatomical lesions tend to be permanent, as shown on MRI on patients who had been intoxicated 25 years previously. ${ }^{58}$
22 Garland H, Pearce J. Neurological complications of carbon monoxide poisoning. $Q \mathcal{f} \mathrm{Med}$ 1967; 144: 445-55.

23 Fisher J, Rubin KP. Occult carbon monoxide poisoning. Arch Intern Med 1982; 142: 1270-1.

24 Grace TW, Platt FW. Subacute carbon monoxide poisoning, another great imitator. $\mathcal{F} A M A$ oxide poisoning, another

25 Thom SR. Hyperbaric oxygen therapy, a committee report. Undersea and Hyperbaric Medical

26 Heckerling PS, Leikin JB, Terzian CG, et al. Occult carbon monoxide poisoning in patients with acute neurological illness. Clin Toxicol 1990; 28: 29-44.

27 Heckerling PS, Leikin JB, Maturen A, et al. Screening hospital admissions from the emergency department for occult carbon monoxide poisoning. Am f Emerg Med 1990; 8: 301-4.

28 Heckerling PS, Leikin JB, Maturen A. Occult carbon monoxide poisoning: validation of a
prediction model. $\mathrm{Am} \mathcal{F} \mathrm{Med} 1988 ; 84: 251-6$

29 Srediction model. Am RS, Stewart RS, Stamm W, et al. Rapid estimation of carboxy-haemoglobin levels in fire fighters. $¥ A M A$ 1976; 235: 390-2

30 Wald NJ, Idle $M$, Boreham J, Bailey A. Carbon monoxide in breath in relation to smoking and carboxy-haemoglobin levels. Thorax 1981; 36: 366-9.

31Vegfors M, Lennmarken C. Carboxy-haemoglobinaemia and pulse oximetry. $B r \mathcal{F}$ Anaesth 1991 66: 635-6.

32 Grim PS, Gottlieb LJ, Boddie MD,et al. Hyperbaric oxygen therapy. $\mathcal{F} A M A 1990 ; 263$ : 2216-20.

33 Moon RE, Piantadosi CA, Francica PJ, et al. Carbon monoxide intoxication. In: Hyperbaric oxygen report. FG Hall Hypo/ Hyperbaric Center, oxygen report. FG Hall Hypo/Hyperbaric Center,

34 Sawada Y, Takahashi M, Ohashi N, et al. Computerised tomography as an indication of Computerised tomography as an indication of long term outcome after acute carbon

35 Myers RAM, Snyder SK, Lindberg S, Cowley $R A$. Value of hyperbaric oxygen in suspected carbon monoxide poisoning. $\mathscr{F} A M A 1981 ; 246$ 2478-80.

36 Norkool DM, Kikpatrick JN. Treatment of acute carbon monoxide poisoning with hyperbaric oxygen: a review of 115 cases. Ann Emerg Med 1985; 14: 1168-71.

37 Neubauer RA. Carbon monoxide and hyperba ric oxygen. Arch Intern Med 1979; 139: 829.

38 Thom SR, Taber RL, Mendiguren II, et al. Delayed neuropsychologic sequelae after carbon monoxide poisoning. Prevention by treatment monoxide poisoning. Prevention by treatment with hyperbaric $474-80$.

39 Sloan EP, Murphy DG, Hart R, et al. Complications and protocol, considerations in carbon monoxide poisoned patients who require hyperbaric oxygen therapy: report from 10 yea experience. Ann Emerg Med 1989; 18: 629-34.

40 Elkharrat D, Raphael JC, Korach JM, et al. Acute carbon monoxide intoxication and hyperbaric oxygen in pregnancy. Intensive Care Med 1991; 17: 289-92.

41 Koren G, Sharav T, Pastuszak A, et al. A multicenter, prospective study of fetal outcome following accidental carbon monoxide poisoning
in pregnancy. Reprod Toxicol 1991; 5: 397-403.
42 Brown DB, Mueller GL, Fairchild AFB. Hyperbaric oxygen treatment for carbon monoxide poisoning in pregnancy. A case report. Aviat Space Environ Med 1992; 63: $1011-4$.

43 Gorman DF, Clayton D, Gilligan JE, Webb RK. A longitudinal study of 100 consecutive admissions for carbon monoxide poisoning to the Royal Adelaide Hospital. Anaesth Intensive Care 1992; 20: 311-6.

44 Fernan JL, Hirsh BE, Derkay C, et al. Hyperbaric oxygen therapy: effect on middle ear and eustachian tube function. Laryngoscope 1992; 102: 48-52.

45 Murphy DG, Sloan EP, Hart RG, Narishiman $\mathrm{K}$, Barreca RS. Tension pneumthorax accociated with hyperbaric oxygen therapy. $\mathrm{Am}$ Emerg Med 1991; 9: 176-9.

46 Winter PM, Miller JN. Carbon monoxide poisoning. $f A M A$ 1976; 236: 1502-4

47 Myers RAM, Snyder SK, Majeus TC. Cutaneous blisters and carbon monoxide poisoning. Ann Emerg Med 1985; 14: 603-6.

48 Balzan MV, Cacciottolo JM. Intestinal infarction following carbon monoxide poisoning. Postgrad Med f 1993; 69: 302-3

49 Florkowski CM, Rossi ML, Carey MP, et al. Rhabdomyolysis and acute renal failure after acute carbon monoxide poisoning. Two case reports with muscle histopathology and enzyme activities. Clin Toxicol 1992; 30: 443-54.

50 Chang $\mathrm{KH}$, Han MH, Kim HS, et al.Delayed encephalopathy after acute carbon monoxide intoxication. MR imaging features and distribution of cerbral white matter lesions. Radiology 1992; 184: 117-22.

51 Min SK. A brain syndrome associated with delayed neuropsychiatric sequelae following acute carbon monoxide intoxication. Acta Psychiat Scand 1986; 73: 80-6.

52 Choi IS. Delayed neurological sequelae in carbon monoxide intoxication. Arch Neurol 1983; 40: 433-5.

53 Finck PA. Exposure to carbon monoxide. Review of the literature and 567 autopsies. Milit Med 1966; 131: 1513

54 Choi IS, Kim SK, Choi YC, et al. Evaluation of outcome after acute carbon monoxide poisonin by brain CT. F Korean Med Sci 1993; 8: 78-83.

55 Qin J. Related factors for the developement of delayed encephalopathy following acute carbon monoxide poisoning. Chung Hua Yu Fang I Hsueh Tsa Chih 1992; 26: 25-7.

56 Murata T, Itoh S, Koshino Y, et al. Serial proton resonance spectroscopy in a patient with the interval form of carbon monoxide poisoning. $\mathcal{f}$ interval form of carbon monoxide poisoning. $\mathcal{F}$

57 Lee MS, Marsden CD. Neurological sequelae following carbon monoxide poisoning. Clinical course and outcome according to the clinical types and brain computed tomography scan findings. Mov Disord 1994; 9: 550-8.

58 Uchino A, Hasuo K, Shida K, et al. MRI of the brain in chronic carbon monoxide poisoning. Neuroradiology 1994; 36: 399-401. 